\title{
Discovery of potential targets of Triptolide through inverse docking in ovarian cancer cells
}

\author{
Qinhang Wu ${ }^{\text {Corresp., }}{ }^{1}$, Gang Bao ${ }^{1}$, Yang Pan ${ }^{1}$, Xiaoqi Qian ${ }^{1}$, Furong Gao ${ }^{1}$ \\ ${ }^{1}$ Department of Pharmacy, Nanjing University of Chinese Medicine, Nanjing, Jiangsu, China \\ Corresponding Author: Qinhang Wu \\ Email address: 328236421@qq.com
}

Triptolide (TPL) is proposed as an effective anticancer agent known for its anti-proliferation of a variety of cancer cells including ovarian cancer cells. Although some studies have been conducted, the mechanism by which TPL acts on ovarian cancer remains to be clearly described. Herein, systematic work based on bioinformatics was carried out to discover the potential targets of TPL in SKOV-3 cells. TPL induces the early apoptosis of SKOV-3 cells in a dose- and time-dependent manner with an $\mathrm{IC}_{50}=40 \pm 0.89 \mathrm{nM}$ when cells are incubated for 48h. Moreover, $20 \mathrm{nM}$ TPL significantly promotes early apoptosis at a rate of $40.73 \%$. Using a self-designed inverse molecular docking protocol, we fish the top nineteen probable targets of TPL from the target library which are built on 2250 proteins extracted from the Protein Data Bank. The 2D-DIGE assay reveals that the expression of eight genes is affected by TPL. The results of western blotting and qRT-PCR assay suggest that $40 \mathrm{nM}$ of TPL up-regulates the level of Annexin A $5(6.34 \pm 0.07$ fold $)$ and ATP syn thase (4.08 \pm 0.08 fold), and down-regulates the level of $\beta$-Tubulin ( $0.11 \pm 0.12$ fold) and HSP90 ( $0.21 \pm 0.09$ fold). More details of TPL affecting on Annexin A5 signaling pathway will be discovered in the future. Our results define some potential targets of TPL, with the hope that this agent could be used as therapy for the preclinical treatment of ovarian cancer. 
1 Discovery of potential targets of Triptolide through inverse

2 docking in ovarian cancer cells

3 Qinhang $\mathrm{Wu}^{1}{ }^{\text {, }}$ Gang Bao ${ }^{1}$, Yang Pan ${ }^{1}$, Xiaoqi Qian ${ }^{1}$, Furong Gao ${ }^{1}$

$4{ }^{1}$ Department of Pharmacy, Nanjing University of Chinese Medicine, Nanjing 210038, China

6 Corresponding Author:

7 Qinhang $\mathrm{Wu}^{1}$

8138 Xianlin Road, Nanjing, Jiangsu, 210038, China

$9 \quad$ Email address: wuqinhang@163.com

10

11

12

13

14

\begin{abstract}
Triptolide (TPL) is proposed as an effective anticancer agent known for its anti-proliferation of a variety of cancer cells including ovarian cancer cells. Although some studies have been conducted, the mechanism by which TPL acts on ovarian cancer remains to be clearly described.

Herein, systematic work based on bioinformatics was carried out to discover the potential targets of TPL in SKOV-3 cells. TPL induces the early apoptosis of SKOV-3 cells in a dose- and time-dependent manner with an $\mathrm{IC}_{50}=40 \pm 0.89 \mathrm{nM}$ when cells are incubated for $48 \mathrm{~h}$. Moreover, 20 nM TPL significantly promotes early apoptosis at a rate of $40.73 \%$. Using a self-designed inverse molecular docking protocol, we fish the top nineteen probable targets of TPL from the target library which are built on 2250 proteins extracted from the Protein Data Bank. The 2D-DIGE assay reveals that the expression of eight genes is affected by TPL. The results of western blotting and qRT-PCR assay suggest that $40 \mathrm{nM}$ of TPL up-regulates the level of Annexin A5 (6.34 \pm 0.07 fold) and ATP synthase (4.08 \pm 0.08 fold), and down-regulates the level of $\beta$-Tubulin $(0.11 \pm 0.12$ fold) and HSP90 (0.21 \pm 0.09 fold). More details of TPL affecting on Annexin A5 signaling pathway will be discovered in the future. Our results define some potential targets of TPL, with the hope that this agent could be used as therapy for the preclinical treatment of ovarian cancer.
\end{abstract}

Key words: Triptolide, ovarian cancer, SKOV-3 cell, inverse docking, potential targets

\title{
1 Introduction
}

Ovarian cancer is currently a leading cause of mortality among gynecological malignant tumors. ${ }^{1}$ Ovarian cancer is derived from the ovarian surface epithelial layer surrounding the ovary and has a high rate of metastasis. ${ }^{2}$ The introduction of combination therapy using paclitaxel and cisplatinum-based drugs can dramatically improve survival rates. ${ }^{3}, 4$ However, traditional chemotherapy drugs have significant adverse side effects and cause to drug resistance of most patients who are initially responsive to this therapy. ${ }^{4}$ Therefore, it needs to discover innovative approaches for the treatment of endometrial and ovarian cancer.

Numerous natural products extracted from plants have been proved to be potent compounds to suppress cancer cells, ${ }^{5}$ for example the clinical anticancer drugs of paclitaxel ${ }^{6}$, etoposide ${ }^{7}$, 
${\text { camptothe } \operatorname{cin}^{8} \text {, and vincristine }}^{9}$. Triptolide (TPL), a diterpene trioxide, is a key component of traditional Chinese medicine Tripterygiumwilfordii Hook. F. (also known as Thunder God Vine) ${ }^{10}$. It is biologically active against autoimmune diseases, inflammation, and various human malignant tumors by inhibiting the proliferation of cancer cells. ${ }^{11} \mathrm{TPL}$ is also proved to be more effective than cisplatinum, taxol, and camptothecin in inhibiting xenograft growth of some solid tumors. Researchers have reported to us that TPL could be considered as a potential chemotherapeutic for ovarian cancer. ${ }^{12,13}$ However, its antitumor activity against gynecologic carcinomas has not yet been well investigated.

One hypothesis that TPL covalently modifies proteins via epoxide ring-opening reactions has been proved that how TPL stimulates apoptosis of cancer cells. ${ }^{14}$ Even the target proteins are undefined, it is evident that TPL has some kind of explained effects on the anticancer. However, with the discovery of other mechanisms, TPL can suppress kinases or suggest epigenetic modifications through alkylation. ${ }^{15-18}$ Chang and Rosen have reported that TPL blocked p53mediated cell cycle arrest to enhance doxorubicin-mediated apoptosis of tumor cells. ${ }^{19}$ Other studies have proved that NFKB, a potential target of TPL, can sensitize TNF-related apoptosisinducing ligand-induced apoptosis in lung cancer cells. ${ }^{20}$ The connection between the antitumor activity of TPL and ovarian cancer remains to be discovered with novel methods.

We sought to use a new bioinformatics method to identify potential targets of TPL in SKOV-3 cells (one of the ovarian cancer cell lines) combining the bioassay and inverse docking ${ }^{21,22}$ to save energy and money. Herein, inverse docking is carried out in the first step to screen proteins extracted from protein/ligand complexes, which are downloaded from Protein Data Bank (PDB, https://www.rcsb.org $)^{23-25}$. On the one hand, the binding sites can be generated automatically using the docking algorithm by identifying the place where native ligands place, on the other hand, it can be defined by reviewing the kinds of literature involved.

Firstly, SKOV-3 cells are incubated for $48 \mathrm{~h}$ to test the anti-proliferative activity of TPL. Secondly, the inverse docking protocol is employed to screen anti-cancer targets of TPL. Thirdly, a 2D-DIGE assay is utilized to further identify targets by testing differential gene expression in TPL-treated SKOV-3 cells from those screened proteins by inverse docking. Finally, western blotting and the qRT-PCR assay define the potential targets at the molecular level.

\section{Materials and Methods}

\subsection{Drug preparation}

TPL (purity 99.0\%, Beijing beihua hengxin biotechnology Co., Ltd) and cisplatinum (P4394, Sigma-Aldrich Co. LLC) were dissolved in dimethyl sulfoxide (DMSO) to a stock concentration of $500 \mathrm{nM}$. The solution was stored at $-20^{\circ} \mathrm{C}$, and diluted in a cell culture medium.

\subsection{Cell Culture}

Human ovarian cancer cell line SKOV-3 (ATCC: HTB-77) were cultured on cell plates at $37^{\circ} \mathrm{C}$, in $5 \% \mathrm{CO}_{2}$, in RPMI-1640 (HyClone) supplemented with $10 \%$ fetal bovine serum, 100 units $/ \mathrm{ml}$ penicillin, and $0.1 \mathrm{mg} / \mathrm{ml}$ streptomycin.

\subsection{MTT assay}

SKOV-3 cells were plated in the 96 -well plates $\left(5 \times 10^{3} /\right.$ well). RPMI- 1640 culture medium was 
used as the blank control group. A final concentration of $0,3,6,12,24,48,96,192,384 \mathrm{nM}$ of TPL and $0,1.25,2.5,5,10,20,40,80,160 \mu \mathrm{M}$ of cisplatinum (used as the positive control) were added to the wells for 24, 48 and $72 \mathrm{~h}$. Five duplicates were set for each concentration. MTT (20 $\mu \mathrm{l}, 5 \mathrm{mg} / \mathrm{ml}$, Sigma, St. Louis, MO) was added to each well at $37^{\circ} \mathrm{C}$ for $4 \mathrm{~h}$. Then $150 \mu \mathrm{L}$ of DMSO was added to each well after the liquid supernatant was removed. The enzyme-linked immunosorbent assay reader (TECAN, SPARK 10M) was used to obtain the results at $570 \mathrm{~nm}$. The $\mathrm{IC}_{50}$ values of TPL and cisplatinum were calculated by SPSS Software (IBM Inc., New York, USA, version 21.0).

\subsection{Apoptosis assay}

After harvested and washed twice SKOV-3 cells were stained with $2 \mu \mathrm{M} \mathrm{JC}-1$ for 15 min at $37^{\circ} \mathrm{C}$. A flow cytometer using $480 \mathrm{~nm}$ excitation and $585 \mathrm{~nm}$ emission filters was applied to analyze the stained wells. Cell suspension mixed with $10 \mu \mathrm{M}$ Carbonyl cyanide m-chlorophenyl hydrazine (CCCP) was set as the control. The cell mixture was incubated for $15 \mathrm{~min}$ at $25^{\circ} \mathrm{C}$ in the dark followed by fluorescence-activated cell sorting (FACS) cater-plus flow cytometry (FACSAria III, BD CellQuest pro).

\subsection{Inverse docking}

Classical biological methods to find the antitumor targets of natural products usually consume manpower and material resources. New approaches such as inverse docking are developed to efficiently fish the potential targets of natural products like resveratrol ${ }^{26}$, cassiar in alkaloids ${ }^{27}$ and curcumin $^{22}$. To identify the potential targets of TPL, we developed an inverse docking protocol ${ }^{28}$ by using a GOLD program (Genetic Optimization for Ligand Docking, version 3.5) ${ }^{29}$ in combination with Discovery Studio (DS, BIOVIA ${ }^{\mathrm{TM}}$, version 4.0).

TPL was subjected to DS as the template ligand. The target library was built based on 2250 protein/ligand complexes extracted from PDB (supplied by BIOVIA ${ }^{\mathrm{TM}}$, updated to 2015). Each protein was standardized with DS Prepare Protein protocol where missed loops were inserted, protonation was performed for $\mathrm{pH}$ of 7.4 with the "Protein Ionization" method, and CHARMm forcefield was used for calculations while native ligands, as well as water, were deleted. Then, the pockets where the native ligands placed were defined as the binding sites. The radius of the docking-grid sphere was set to $1.5 \mathrm{~nm}$ to accommodate the entire TPL molecule as long as at least one of its atoms is placed less than $0.6 \mathrm{~nm}$ away from the binding sites. The inverse docking protocol applied semi-flexible docking based on a genetic algorithm to save the CPU time and acquire accurate docking results. ${ }^{30}$ The algorithm sets the ligand and binding sites flexible to generate 255 poses while the other region of the protein rigid. The inverse docking search protocol could successfully dock TPL into a candidate protein before all possible positions and orientations of 255 poses were exhausted. At most five poses were stored from every docking simulation, except if the best three docking poses had root-mean-square deviations (RMSD) smaller than 0.15 $\mathrm{nm}$. The Xray_Score calculated by GoldScore and Ludi_score was used to score and rank the poses of inverse docking (see in supplementary file).

\subsection{D Gel Electrophoresis}

SKOV-3 cells treated with TPL were washed twice with ice-cold PBS and resuspended in lysis buffer for $30 \mathrm{~min}$ to collect the cell suspension. After incubated for $15 \mathrm{~min}$ at $25^{\circ} \mathrm{C}$, samples were 
mixed with $N, N$-dimethylacrylamide for alkylation and DTT for centrifugation. Protein samples were separated by 2D gel electrophoresis using the first dimension, isoelectric focusing (IEF), and the second dimension, non-equilibrium $\mathrm{pH}$ gradient electrophoresis (NEPHGE). The first dimension was performed with a nonlinear $\mathrm{pH} 3-10$ range at $25^{\circ} \mathrm{C}$ in IEF buffer $(0.5 \%$ Pharmalyte 3-10 NL, 2\% (w/v) ASB, 15 mM DTT, 2 M thiourea, $6 \mathrm{M}$ urea and bromophenol blue) containing $0.16 \mathrm{mg}$ labeled proteins. After IEF, the immobiline strip with separated proteins was equilibrated for 15 min using equilibration buffer (Thermo Fisher Scientific). Separated protein samples were then further separated on 4-12\% polyacrylamide gel. After labeling with Cy3- or Cy5- fluorescent dye, gels were scanned on a 2920 2D-Master Imager (Bio-Rad) according to manufacturer's instruction. Protein spots were migrated and detected automatically, then quantified by calculating the fluorescence intensities using DeCyder Differential In-Gel Analysis Software (Bio-Rad).

\subsection{Peptide Mass Fingerprinting}

Protein spots excised from the gel were destained with trypsin (Sigma Aldrich) then incubated in MilliQ- $\mathrm{H}_{2} \mathrm{O}$ for 10 min to cut into small pieces. Peptides were extracted twice from supernatants of the disposed of gel pieces with $50 \%(\mathrm{v} / \mathrm{v})$ acetonitrile and $0.1 \%(\mathrm{v} / \mathrm{v})$ trifluoroacetic acid. After pooled and dried, extracts were analyzed using a TofSpec-2E mass spectrometer (Micromass, Manchester, UK). Peptide mass fingerprinting maps were acquired and screened in the Swiss-Prot database performed by the Mascot Software.

\subsection{Western Blotting}

Cells were washed twice and lysed in ice-cold RIPA lysis buffer for $30 \mathrm{~min}$ to collect the cell suspension. After separated with SDS-PAGE, cell lysate aliquots $(40 \mu \mathrm{g})$ were blotted onto a polyvinylidene difluoride membrane and incubated with primary antibody, rabbit polyclonal antiAnnexin A5 (diluted 1:300; Abcam), anti-ATP synthase (diluted 1:300; Abcam), anti- $\beta$-tubulin (diluted 1:300; Abcam) and anti-HSP90 (diluted 1:300; Abcam) overnight at $4^{\circ} \mathrm{C}$. Membranes were washed and incubated with goat anti-rabbit IgG horseradish-peroxidase (HRP) preadsorption secondary antibody (1:2000; ab7090, Abcam). Bands were visualized by an enhanced chemiluminescence system (ECL, Abcam), then quantified using the manufacturer protocol (BioRad). The PowerPacTM HC electrophoresis instrument and film transfer instrument (Bio-Rad, California, USA) was used in this section.

\subsection{RNA isolation and quantitative real-time PCR}

Total RNA was extracted from SKOV-3 cells treated with TPL $(0,10,20,40 \mathrm{nM}$ for $48 \mathrm{~h})$ using the RNA extraction kit (Invitrogen, Life Technologies, CA). cDNA was synthesized from $2 \mu \mathrm{g}$ of total RNA using Superscript reverse transcriptase (Life Technologies, CA). The primers used for quantitative real-time PCR (qRT-PCR) were as follows: for HSP90, sense primer (5'TTAAGGTACTACACATCTGCCTCT-3') and antisense primer (5'TGCTTTCGGAGACGTTCCACAA-3'); for Annexin A5, sense primer (5'CAGTCTAGGTGCAGCTGCCG-3') and antisense primer (5'GGTGAAGCAGGACCAGACTGT-3') ; for ATP synthase, sense primer (5'TCTTTGCTGGTGTTGGTGAA-3') and antisense primer (5'-TGAGCTCATCCATACCCAAA$\left.3^{\prime}\right)$; for $\beta$-tubulin, sense primer (5'-TGCATTGACAACGAGGC-3') and antisense primer (5'CTGTCTTGACATTGTTG-3'). The housekeeping gene glyceraldehyde phosphate 
161 dehydrogenase (GAPDH) was used for normalization (sense: 5'162 TGATGACATCAAGAAGGTGGTGAAG-3'; and antisense: 5'-TCCTTGGAGGCCATGTG 163 GGCCAT-3'). PCR products were analyzed by $1.2 \%$ agarose gel electrophoresis with ethidium 164 bromide for UV light transilluminator visualization using LightCycler $^{\circledR} 96$ qRT-PCR instrument 165 (Roche Life Science).

166

\subsection{Statistical analyses}

Statistical analysis was performed by using one-way analysis of variance, followed by Dunnett's Multiple Comparison T-test using SPSS Software (IBM Inc., New York, USA, version 21.0) when appropriate. All data were presented as mean \pm standard deviation (SD). The difference was considered statistically significant at ${ }^{*} p<0.05$ and ${ }^{* *} p<0.01$.

\section{Results}

\subsection{Evaluation of the anti-cancer effect of TPL on SKOV-3 cell line}

The efficacy of TPL on ovarian cancer and its target genes have not been deeply studied. To test the ability of TPL to inhibit the survival of ovarian cancer cell in vitro, cell viability assay using the SKOV-3 cell line was performed. Compared to cisplatinum, TPL exhibits a better potency with $\mathrm{IC}_{50}$ values of the nanomolar level. Significant suppression of proliferation in SKOV-3 cells is observed after treatment with TPL at the concentrations of 3, 6, 12, 24, 48, 96,192 and $384 \mathrm{nM}$ respectively (Figure 1). When the TPL dose increased, a gradual decrease in cell viability is observed either cells are treated for 24,48 or 72 hours. At the concentration of 3 and $6 \mathrm{nM}$, little significant time dependence of cell treatment for 24,48 or 72 hours was observed. Along with the increasing concentration, the time dependence becomes clear among 24, 48 and 72 hours. It can also be seen in Table 1, TPL exhibits the $\mathrm{IC}_{50}$ value of $70.3 \pm 1.17 \mathrm{nM}$ and $31.7 \pm 1.23 \mathrm{nM}$ on 24 and $72 \mathrm{~h}$. Meanwhile, cisplatinum exhibits larger $\mathrm{IC}_{50}$ value of $33.0 \pm 1.77 \mu \mathrm{M}$ and $9.6 \pm 0.74 \mu \mathrm{M}$ on 24 and $72 \mathrm{~h}$. All the data show that TPL inhibits ovarian cancer cell proliferation more potently than cisplatinum in a dose-dependent manner in SKOV-3 cell lines.

Table 1 . The $\mathrm{IC}_{50}$ value of different drugs on SKOV-3 cells

Figure 1. (A) The chemical structure of TPL. (B) Effects of TPL on the growth of endometrial and SKOV-3 cell in vitro. ${ }^{*} p<0.05$ vs. Control

\subsection{Apoptotic changes in TPL-treated ovarian cancer cell}

As the increased doses of TPL, we also detected a simultaneous increase in both LR fraction (early apoptosis) and LL fraction (regarded as necrotic) subpopulations. As is shown in Figure 2A, the degree of apoptosis is quantitatively expressed as the control (DMSO) presented 13.20\% population after $24 \mathrm{~h}$ treatment. The apoptosis rate of SKOV-3 cell rises after the treatment of TPL. Both the low and high concentrations of TPL significantly promote the apoptosis of SKOV-3 cells with the early apoptosis rate of $26.25 \%$ and $40.73 \%$ (Figure $2 \mathrm{~B}$ ). In contrast to low concentration, a high concentration of TPL slightly enhances the apoptosis of SKOV-3 cells and is higher than 
201

202

203

204

205

206

207

208

209

210

211

212

213

214

215

216

217

218

219

220

221

222

223

224

225

226

227

228

229

230

231

232

233

234

235

236

237

238

239

240

241

those treated with $10 \mu \mathrm{M}$ CCCP. A dose-dependent increase of early apoptosis can also be seen from the results after TPL treatment of SKOV-3 cells. The results of the apoptosis assay indicate that TPL inhibits SKOV-3 cells by inhibiting certain targets rather than by killing cytotoxic SKOV-3 cells.

Figure 2. (A) Flow cytometric analysis of SKOV-3 cells using the MitoProbe JC-1 Assay Kit. (B) The histogram of the results of flow cytometric analysis. DMSO as the blank, CCCP $(10 \mu \mathrm{M})$ as the control, TPL $(10 \mathrm{nM})$ and TPL $(20 \mathrm{nM})$ on the apoptosis of SKOV-3 cells. ${ }^{*} p<0.05$ vs. Control

\subsection{Inverse docking}

Interestingly, TPL is more active than cisplatinum. To find potential target genes of TPL, an inverse docking protocol in silico was designed based on GOLD. With ranked Xray_Score values calculated by the GOLD scoring protocol, the top 19 poses with the Xray_Score values larger than 150 were selected (see in supplemental files). Among them, seven poses (5lnz, $4 \mathbf{b q g}, \mathbf{2 q f 6}, \mathbf{2} \mathbf{x a b}$, 2brc, 2xab, 2yki) belong to HSP90, six proteins (5j2t, 5iyz, 4o2a, 4drx, 4o2b, 4tuy) belonged to $\beta$-Tubulin, three proteins (2xo2, 2h0m, 1yii) belong to Annexin A5 and three proteins (5dn6, 3m4y, 2wpd) belong to ATP synthase respectively (Figure 3A). HSP90 protein has the highest docking scores compared with the other three proteins. As in Figure 4B, two hydrogen bonds between TPL and HSP90, Ser52 and Gly135 ensure the correct binding pose of TPL, as well as hydrophobic interactions, stabilize the binding mode. However, the amount of HSP90 proteins are not significantly different from other proteins. Therefore, further biological experiments are necessary to identify the potential targets for TPL.

Figure 3. (A) Inverse_docking scores calculated by GOLD for the top 19 proteins. (B) The docking pose of TPL binding to HSP90 (PDB ID: 5LNZ). The binding pocket of HSP90 protein displayed as an $\alpha$-helix with a surface. All compounds are shown with only backbone atoms.

\subsection{Differential gene expressions in TPL-treated SKOV-3 cell}

To further determine the main targets of TPL on ovarian cancer cells, a 2D-DIGE assay was utilized to examine global changes in gene expression in SKOV-3 cells after treatment with 10nM TPL for $48 \mathrm{~h}$. Total proteins from SKOV-3 cell were minimally labeled with two different fluorescent dyes, mixed, and separated by isoelectric focusing on a 2D gel on SDS-PAGE. The identical proteins migrating to the same 2D spots were detected and quantified based on their fluorescence intensities to compare their expression by the DeCyder program.

The difference of spots' density between normal and TPL-treated SKOV-3 cells discloses the changes of expression in eighteen protein spots (Figure 4). Among 18 protein spots, the density between TPL and control is larger than 2 in eight spots. They are chosen to acquire finger printers of the peptide mass via MS/MS spectrum. According to the database searching results, the eight proteins are verified as Annexin A5, Tropomyosin (alpha-3 chain), ATP synthase (subunit beta), POTE ankyrin (domain family member E), Rho (GDP-dissociation inhibitor), Actin (cytoplasmic), Tubulin ( $\beta$-4B chain) and Heat shock protein 90-alpha (HSP90). The representative genes found to be up- and down-regulated by $10 \mathrm{nM}$ of TPL treatment are summarized in Tables 2, respectively. 
242 Their known or proposed functions are analyzed by Gene Ontology. These eight proteins are

243

244

245

246

247

248

249

250

251

252

253

254

255

256

257

258

259

260

261

262

263

264

265

266

267

268

269

270

271

272

273

274

275

276

277

278

279

mostly involved in maintaining the cellular structure, signal transduction, and transport.

Figure 4. Differential expression profile of SKOV-3 proteome between 0 and $10 \mathrm{nmol} / \mathrm{L}$ TPL based on 2DDIGE.

Table 2. Up-regulated and down-regulated genes after treatment with TPL in SKOV-3 cells.

\subsection{Effects of TPL on the expression of novel proteins}

To further elucidate the mechanism of TPL in ovarian cancer and define the main target gene, Western Blotting (WB) and qRT-PCR analysis were performed on the four proteins to detect their differential expression. The results (shown in Figure 5 and Table 3) reveal that TPL markedly upregulates the levels of Annexin A5 and ATP synthase proteins as well as down-regulates the levels of $\beta$-Tubulin and HSP90 in ovarian cancer cell lines. WB results show that the expression of Annexin A5 and ATP synthase increases in a dose-dependent manner after TPL treatment for 24 hours. According to qRT-PCR assay results, TPL stimulates the expression of Annexin A5 at 40 $\mathrm{nM}$, especially more dramatically than ATP synthase $(6.34 \pm 0.07$ fold vs $4.08 \pm 0.08$ fold $)$. On the other hand, TPL inhibited $\beta$-Tubulin and HSP90 significantly more than 50\% at the concentration of 20 and $40 \mathrm{nM}$. When cells are treated with $40 \mathrm{nM}$ TPL. The relative expression of $\beta$-Tubulin mRNA decreases from 1 to $0.11 \pm 0.12$ fold.

Figure 5. (A) Validation of differential expression proteins by Western Blotting. (B) The histogram of the relative protein expression levels (equates to protein $/ \beta$-actin). ${ }^{*} p<0.05$ vs. Control .... ${ }^{*} p<0.01$ vs. Control

Table 3. Expression amount of relative mRNA in SKOV-3 cells treated with TPL in the qRT-PCR assay. ( $\mathrm{n}=3$, mean \pm s)

\section{Discussion}

TPL, a pure compound extract from the Chinese traditional medicine T. wilfordii, has significant cytotoxic effects on ovarian cancer. ${ }^{14}$ However, the mechanisms of TPL on ovarian cancer and its target genes have not been studied. ${ }^{12}$ Herein, systematic work was performed to discover some transcription factors in SKOV-3 cell when treated with TPL. In contrast to cisplatinum, TPL significantly increases the number of apoptotic cells in ovarian cancer cell lines. More than 50\% of cell apoptosis is observed when the SKOV-3 cell is treated with $48 \mathrm{nM}$ for $48 \mathrm{~h}$. Besides, the annexin $\mathrm{V}$ assay can detect that $40 \mathrm{nM}$ TPL dramatically promotes early apoptotic cells at the rate of $40.73 \%$. It means that apoptosis slowly induces in SKOV-3 cells. These results suggest that 
280

281

282

283

284

285

286

287

288

289

290

291

292

293

294

295

296

297

298

299

300

301

302

303

304

305

306

307

308

309

310

311

312

313

314

315

316

317

318

319

TPL could be investigated as a possible therapeutic agent for ovarian cancer. However, the mechanism by which TPL exerted its anticancer activities and the target genes TPL up- or downregulated remains unclear.

To find its potential target from many proteins, an inverse docking protocol was developed based on the GOLD program, using TPL as the template ligand to fish the well-docked proteins downloaded from PDB. Four targets from the top 19 proteins are selected with the docking scores larger than 100. However, there is no enough difference between them. To find out more details of TPL acting on the four target genes, the gene expression profile changes in SKOV-3 cells are investigated after the treatment with TPL. Four proteins with the spots' density larger than 2.5 in the 2D-DIGE assay are chosen to quantitatively determine changes in their relative mRNA expression induced by TPL treatment. In SKOV-3 cell treated with $40 \mathrm{nM}$ TPL, mRNA levels of Annexin A5 and ATP synthase are up-regulated to $6.34 \pm 0.07$ and $4.08 \pm 0.08$ fold, while mRNA levels of $\beta$-Tubulin and HSP90 are down-regulated for $0.11 \pm 0.12$ and $0.21 \pm 0.09$ fold.

Initially, TPL has been demonstrated to cause global transcriptional inhibition via the largest subunit of RNA polymerase II. ${ }^{31}$ Recently, TPL is believed to target specific transcription factors, such as Bcl-2, Bcl-xL, NF-kB, pRB, RNA polymerases. ${ }^{32-36}$ In this study, we provide evidence that TPL inhibits $\beta$-tubulin and HSP90. Several natural products including paclitaxel, colchicine, and vinca alkaloids have been proved to bind $\beta$-tubulin at a distinct binding site. ${ }^{37}$ As a natural product isolated from the medicinal plant, TPL effectively reduces $\beta$-tubulin, which means that TPL can inhibit ovarian cancer cells via down-regulation of $\beta$-tubulin. However, more details of the pathway involving $\beta$-tubulin remain unclear and the binding sites on $\beta$-tubulin bound by TPL have yet to be confirmed. As a cellular protein in the annexin group, Annexin A5 binds to anionic phospholipids with high affinity, although the detail function of the protein is unclear. However, Annexin A5 has been proved to be an essential protein in the inhibition of blood coagulation. Recent studies have shown that Annexin A5 inhibits the activity of phospholipase A1 by competing with prothrombin for phosphatidylserine binding sites. ${ }^{38}$ All of these details revealed in several in vitro studies suggest that Annexin A5 plays a key role in the subsistence and apoptosis of cancer cell. ${ }^{39-41}$ The further experiment suggests that Annexin A5 significantly regulates the signaling pathway involved in cell apoptosis on ovarian cancer. ${ }^{39}$ This evidence inspires us that the potential target of TPL effect on ovarian cancer cells could be Annexin A5. More details on how TPL affects Annexin A5 signaling will be revealed in the future.

\section{Conclusion}

We first used the inverse docking in silico to discover targets of TPL at cellular and molecular levels. Although there exist more details about how TPL inhibits SKOV-3 cells, our research suggests that it could be investigated as a possible therapeutic agent for ovarian cancer. Four target genes, Annexin A5, ATP synthase, $\beta$-tubulin, and HSP90, are presented here to be regulated significantly by TPL treatment in SKOV-3 cells. Further work will focus on the signaling pathways which involve in ovarian cancer.

\section{Conflict of interest}

The authors declare that there is no conflict of interest (any financial and personal relationships 
with other people or organizations that could inappropriately influence (bias) our work).

\section{Acknowledgements}

This research was supported by the Doctoral Fund of Ministry of Education of China (20133237120011) and a project funded by the Priority Academic Program Development of Jiangsu Higher Education Institutions (PAPD).

\section{References}

1. Crane, E. K.; Brown, J. Early stage mucinous ovarian cancer: A review. Gynecologic oncology 2018, 149, 598604.

2. Vetter, M. H.; Hays, J. L. Use of Targeted Therapeutics in Epithelial Ovarian Cancer: A Review of Current Literature and Future Directions. Clinical therapeutics 2018, 40, 361-371.

3. Wilson, M. K.; Friedlander, M. L.; Joly, F.; Oza, A. M. A Systematic Review of Health-Related Quality of Life Reporting in Ovarian Cancer Phase III Clinical Trials: Room to Improve. The oncologist 2018, 23, 203-213.

4. Moore, K. N.; Martin, L. P.; O'Malley, D. M.; Matulonis, U. A.; Konner, J. A.; Vergote, I.; Ponte, J. F.; Birrer, M. J. A review of mirvetuximab soravtansine in the treatment of platinum-resistant ovarian cancer. Future oncology 2018, 14, 123-136.

5. Cevatemre, B.; Erkisa, M.; Aztopal, N.; Karakas, D.; Alper, P.; Tsimplouli, C.; Sereti, E.; Dimas, K.; Armutak, E. I. I.; Gurevin, E. G.; Uvez, A.; Mori, M.; Berardozzi, S.; Ingallina, C.; D'Acquarica, I.; Botta, B.; Ozpolat, B.; Ulukaya, E. A promising natural product, pristimerin, results in cytotoxicity against breast cancer stem cells in vitro and xenografts in vivo through apoptosis and an incomplete autopaghy in breast cancer. Pharmacological research 2018, 129, 500514.

6. Nakamura, F.; Seino, M.; Suzuki, Y.; Sakaki, H.; Sudo, T.; Ohta, T.; Tsutsumi, S.; Nagase, S. Successful management of cutaneous lymphangitis carcinomatosa arising from cervical cancer with paclitaxel-cisplatin and bevacizumab combination therapy: a case report and review of the literature. Journal of medical case reports 2019, 13, 328-333.

7. Breitbach, G. P.; Sklavounos, P.; Veith, C.; Costa, S. D.; Kuhn, W.; Solomayer, E. F.; Juhasz-Boess, I.; Tempfer, C. Oral etoposide for metastatic choriocarcinoma: a case report and review of guidelines. Archives of gynecology and obstetrics 2019, 299, 1115-1119.

8. Amin, S. A.; Adhikari, N.; Jha, T.; Gayen, S. A Review on Camptothecin Analogs with Promising Cytotoxic Profile. Anti-cancer agents in medicinal chemistry 2018, 18, 1796-1814.

9. Hafazalla, K.; Sahgal, A.; Jaja, B.; Perry, J. R.; Das, S. Procarbazine, CCNU and vincristine (PCV) versus temozolomide chemotherapy for patients with low-grade glioma: a systematic review. Oncotarget 2018, 9, 3362333633.

10. Chen, B. J. Triptolide, a novel immunosuppressive and anti-inflammatory agent purified from a Chinese herb Tripterygium wilfordii Hook F. Leukemia \& lymphoma 2001, 42, 253-265.

11. Zhang, C.; He, X. J.; Li, L.; Lu, C.; Lu, A. P. Effect of the Natural Product Triptolide on Pancreatic Cancer: A Systematic Review of Preclinical Studies. Frontiers in pharmacology 2017, 8, 490-490.

12. Westfall, S. D.; Nilsson, E. E.; Skinner, M. K. Role of triptolide as an adjunct chemotherapy for ovarian cancer. Chemotherapy 2008, 54, 67-76.

13. Li, H.; Takai, N.; Yuge, A.; Furukawa, Y.; Tsuno, A.; Tsukamoto, Y.; Kong, S.; Moriyama, M.; Narahara, H. Novel 
361

362

363

364

365

366

367

368

369

370

371

372

373

374

375

376

377

378

379

380

381

382

383

384

385

386

387

388

389

390

391

392

393

394

395

396

397

398

399

400

401

target genes responsive to the anti-growth activity of triptolide in endometrial and ovarian cancer cells. Cancer letters 2010, 297, 198-206.

14. Hu, H.; Luo, L.; Liu, F.; Zou, D.; Zhu, S.; Tan, B.; Chen, T. Anti-cancer and Sensibilisation Effect of Triptolide on Human Epithelial Ovarian Cancer. Journal of Cancer 2016, 7, 2093-2099.

15. Sun, Y. Y.; Xiao, L.; Wang, D.; Ji, Y. C.; Yang, Y. P.; Ma, R.; Chen, X. H. Triptolide inhibits viability and induces apoptosis in liver cancer cells through activation of the tumor suppressor gene p53. International journal of oncology 2017, 50, 847-852.

16. Zhong, Y. Y.; Chen, H. P.; Tan, B. Z.; Yu, H. H.; Huang, X. S. Triptolide avoids cisplatin resistance and induces apoptosis via the reactive oxygen species/nuclear factor-kappaB pathway in SKOV3(PT) platinum-resistant human ovarian cancer cells. Oncology letters 2013, 6, 1084-1092.

17. Song, J. M.; Molla, K.; Anandharaj, A.; Cornax, I.; MG, O. S.; Kirtane, A. R.; Panyam, J.; Kassie, F. Triptolide suppresses the in vitro and in vivo growth of lung cancer cells by targeting hyaluronan-CD44/RHAMM signaling. Oncotarget 2017, 8, 26927-26940.

18. Liu, S. P.; Wang, G. D.; Du, X. J.; Wan, G.; Wu, J. T.; Miao, L. B.; Liang, Q. D. Triptolide inhibits the function of TNF-alpha in osteoblast differentiation by inhibiting the NF-kappaB signaling pathway. Experimental and therapeutic medicine 2017, 14, 2235-2240.

19. Chang, W. T.; Kang, J. J.; Lee, K. Y.; Wei, K.; Anderson, E.; Gotmare, S.; Ross, J. A.; Rosen, G. D. Triptolide and chemotherapy cooperate in tumor cell apoptosis. A role for the p53 pathway. The Journal of biological chemistry 2001, 276, 2221-2227.

20. Lee, K. Y.; Park, J. S.; Jee, Y. K.; Rosen, G. D. Triptolide sensitizes lung cancer cells to TNF-related apoptosisinducing ligand (TRAIL)-induced apoptosis by inhibition of NF-kappaB activation. Experimental \& molecular medicine 2002, 34, 462-468.

21. Kamper, A.; Apostolakis, J.; Rarey, M.; Marian, C. M.; Lengauer, T. Fully automated flexible docking of ligands into flexible synthetic receptors using forward and inverse docking strategies. Journal of chemical information and modeling 2006, 46, 903-911.

22. Furlan, V.; Konc, J.; Bren, U. Inverse Molecular Docking as a Novel Approach to Study Anticarcinogenic and AntiNeuroinflammatory Effects of Curcumin. Molecules 2018, 23, 3351-3369.

23. Berman, H. M.; Westbrook, J.; Feng, Z.; Gilliland, G.; Bhat, T. N.; Weissig, H.; Shindyalov, I. N.; Bourne, P. E. The Protein Data Bank. Nucleic acids research 2000, 28, 235-242.

24. Burley, S. K.; Berman, H. M.; Bhikadiya, C.; Bi, C.; Chen, L.; Di Costanzo, L.; Christie, C.; Dalenberg, K.; Duarte, J. M.; Dutta, S.; Feng, Z.; Ghosh, S.; Goodsell, D. S.; Green, R. K.; Guranovic, V.; Guzenko, D.; Hudson, B. P.; Kalro, T.; Liang, Y.; Lowe, R.; Namkoong, H.; Peisach, E.; Periskova, I.; Prlic, A.; Randle, C.; Rose, A.; Rose, P.; Sala, R.; Sekharan, M.; Shao, C.; Tan, L.; Tao, Y. P.; Valasatava, Y.; Voigt, M.; Westbrook, J.; Woo, J.; Yang, H.; Young, J.; Zhuravleva, M.; Zardecki, C. RCSB Protein Data Bank: biological macromolecular structures enabling research and education in fundamental biology, biomedicine, biotechnology and energy. Nucleic acids research 2019, 47, 464-474.

25. Westbrook, J.; Feng, Z.; Chen, L.; Yang, H.; Berman, H. M. The Protein Data Bank and structural genomics. Nucleic acids research 2003, 31, 489-491.

26. Kores, K.; Lesnik, S.; Bren, U.; Janezic, D.; Konc, J. Discovery of Novel Potential Human Targets of Resveratrol by Inverse Molecular Docking. Journal of chemical information and modeling 2019, 59, 2467-2478.

27. Negi, A.; Bhandari, N.; Shyamlal, B. R. K.; Chaudhary, S. Inverse docking based screening and identification of protein targets for Cassiarin alkaloids against Plasmodium falciparum. Saudi pharmaceutical journal : SPJ : the official

Peer) reviewing PDF | (2019:01:34606:2:0:NEW 13 Jan 2020) 
402

403

404

405

406

407

408

409

410

411

412

413

414

415

416

417

418

419

420

421

422

423

424

425

426

427

428

429

430

431

432

433

434

435

436

437

438

439

publication of the Saudi Pharmaceutical Society 2018, 26, 546-567.

28. Bren, U.; Fuchs, J. E.; Oostenbrink, C. Cooperative binding of aflatoxin B1 by cytochrome P450 3A4: a computational study. Chemical research in toxicology 2014, 27, 2136-2147.

29. Jones, G.; Willett, P.; Glen, R. C.; Leach, A. R.; Taylor, R. Development and validation of a genetic algorithm for flexible docking. Journal of molecular biology 1997, 267, 727-748.

30. Xue, X.; Wei, J. L.; Xu, L. L.; Xi, M. Y.; Xu, X. L.; Liu, F.; Guo, X. K.; Wang, L.; Zhang, X. J.; Zhang, M. Y.; Lu, M. C.; Sun, H. P.; You, Q. D. Effective screening strategy using ensembled pharmacophore models combined with cascade docking: application to p53-MDM2 interaction inhibitors. Journal of chemical information and modeling 2013, 53, 2715-2729.

31. Zhao, H.; Yang, Z.; Wang, X.; Zhang, X.; Wang, M.; Wang, Y.; Mei, Q.; Wang, Z. Triptolide inhibits ovarian cancer cell invasion by repression of matrix metalloproteinase 7 and 19 and upregulation of E-cadherin. Experimental \& molecular medicine 2012, 44, 633-641.

32. Wu, J.; Li, Q. Q.; Zhou, H.; Lu, Y.; Li, J. M.; Ma, Y.; Wang, L.; Fu, T.; Gong, X.; Weintraub, M.; Wu, S.; Ding, H. Selective tumor cell killing by triptolide in p53 wild-type and p53 mutant ovarian carcinomas. Medical oncology 2014, 31, 14-24.

33. Zhang, F. Z.; Ho, D. H.; Wong, R. H. Triptolide, a HSP90 middle domain inhibitor, induces apoptosis in triple manner. Oncotarget 2018, 9, 22301-22315.

34. Li, R.; Zhang, X.; Tian, X.; Shen, C.; Zhang, Q.; Zhang, Y.; Wang, Z.; Wang, F.; Tao, Y. Triptolide inhibits tumor growth by induction of cellular senescence. Oncology reports 2017, 37, 442-448.

35. Guan, J.; Zhao, Q.; Lv, J.; Zhang, Z.; Sun, S.; Mao, W. Triptolide induces DNA breaks, activates caspase-3dependent apoptosis and sensitizes B-cell lymphoma to poly(ADP-ribose) polymerase 1 and phosphoinositide 3kinase inhibitors. Oncology letters 2017, 14, 4965-4970.

36. Kim, J. H.; Park, B. Triptolide blocks the STAT3 signaling pathway through induction of protein tyrosine phosphatase SHP-1 in multiple myeloma cells. International journal of molecular medicine 2017, 40, 1566-1572.

37. Zhou, J.; Giannakakou, P. Targeting microtubules for cancer chemotherapy. Current medicinal chemistry. Anticancer agents 2005, 5, 65-71.

38. Zhou, J.; Chang, M.; Li, J.; Fang, T.; Hu, J.; Bai, C. Knockdown of annexin A5 restores gefitinib sensitivity by promoting G2/M cell cycle arrest. Respiratory research 2018, 19, 96-106.

39. Becarevic, M.; Saric, M.; Stojanovich, L.; Mirkovic, D.; Dopsaj, V.; Ignjatovic, S. Anti-annexin A5 antibodies and 25-hydroxy-cholecalciferol in female patients with primary antiphospholipid syndrome. Clinical rheumatology 2018, 37, 3359-3364.

40. Su, J.; Yang, L.; Chen, W.; Liu, L.; Xue, Y. Effects of insulin intervention on the expression of VE-cadherin, betacatenin, Annexin A2, Annexin A5, and 14-3-3 protein in the placentas of patients with gestational diabetes. Minerva endocrinologica 2018, 43, 221-224.

41. Sun, X.; Liu, S.; Wang, J.; Wei, B.; Guo, C.; Chen, C.; Sun, M. Z. Annexin A5 regulates hepatocarcinoma malignancy via CRKI/II-DOCK180-RAC1 integrin and MEK-ERK pathways. Cell death \& disease 2018, 9, 637-647.

Peer] reviewing PDF | (2019:01:34606:2:0:NEW 13 Jan 2020) 
Figure 1

The chemical structure of TPL and the histogram for the anti-cancer effects of TPL on SKOV-3 cell in line.

A) The chemical structure of TPL. B) Effects of TPL on the growth of endometrial and SKOV-3 cell in vitro. ${ }^{*} p \square 0.05$ vs. control

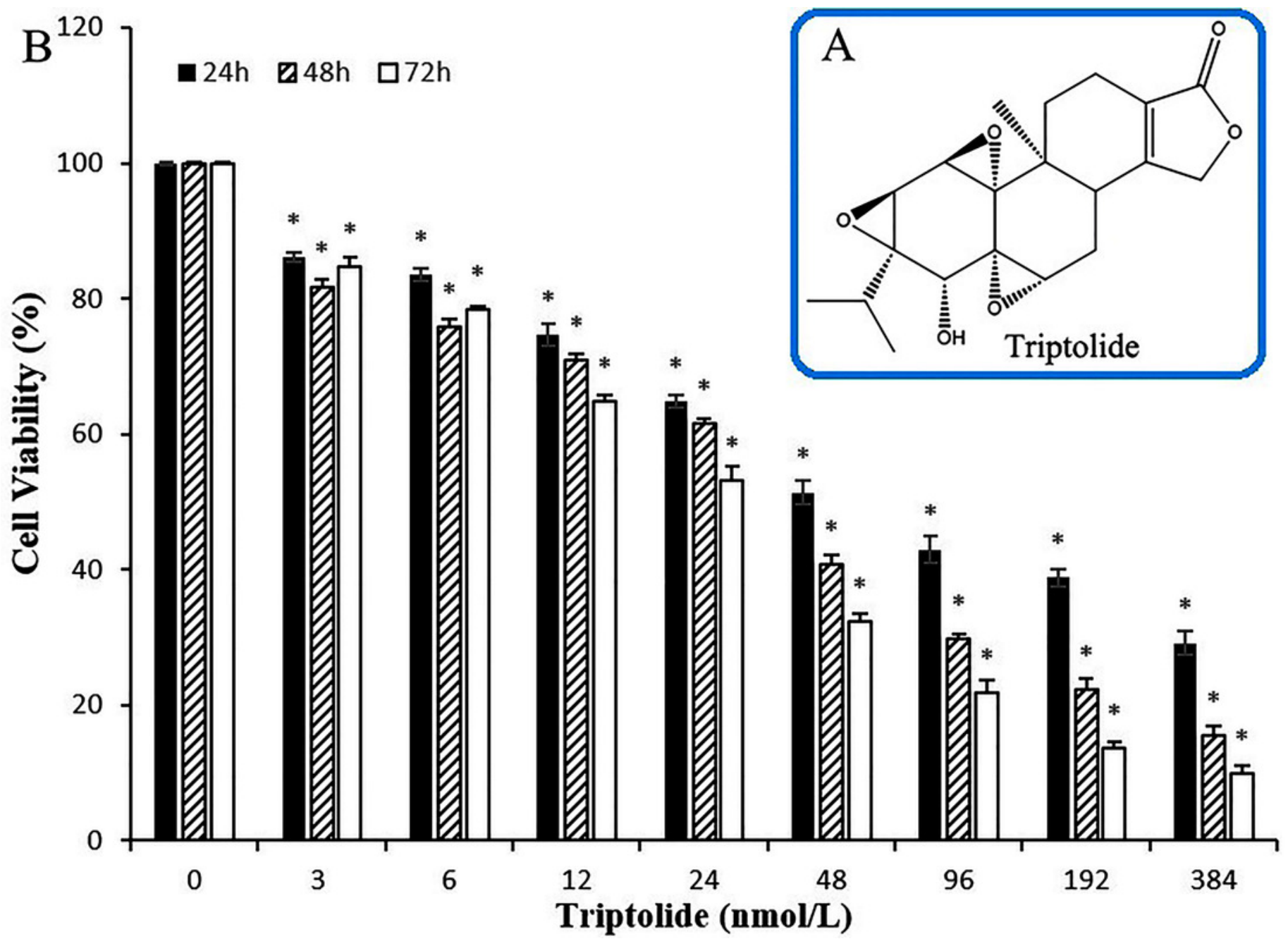


Figure 2

Flow cytometric analysis of SKOV-3 cells using the MitoProbe JC-1 Assay Kit.

Figure 2. (A) Flow cytometric analysis of SKOV-3 cells using the MitoProbe JC-1 Assay Kit. (B) The histogram of the results of flow cytometric analysis. DMSO as the blank, CCCP (10 $\mu \mathrm{M})$ as the control, TPL (10 nM) and TPL (20 nM) on the apoptosis of SKOV-3 cells. *p $\square 0.05$ vs. control 

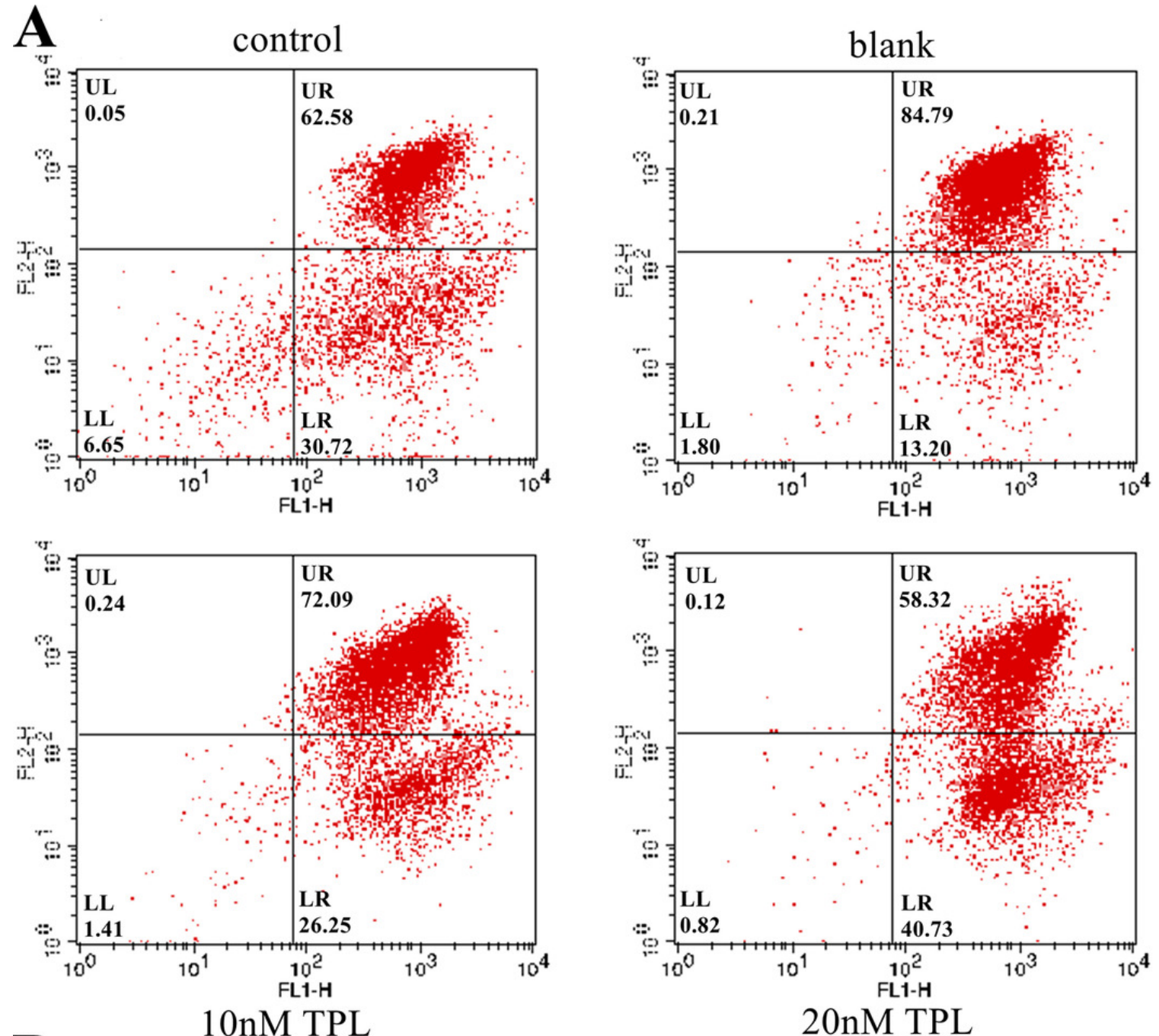

B

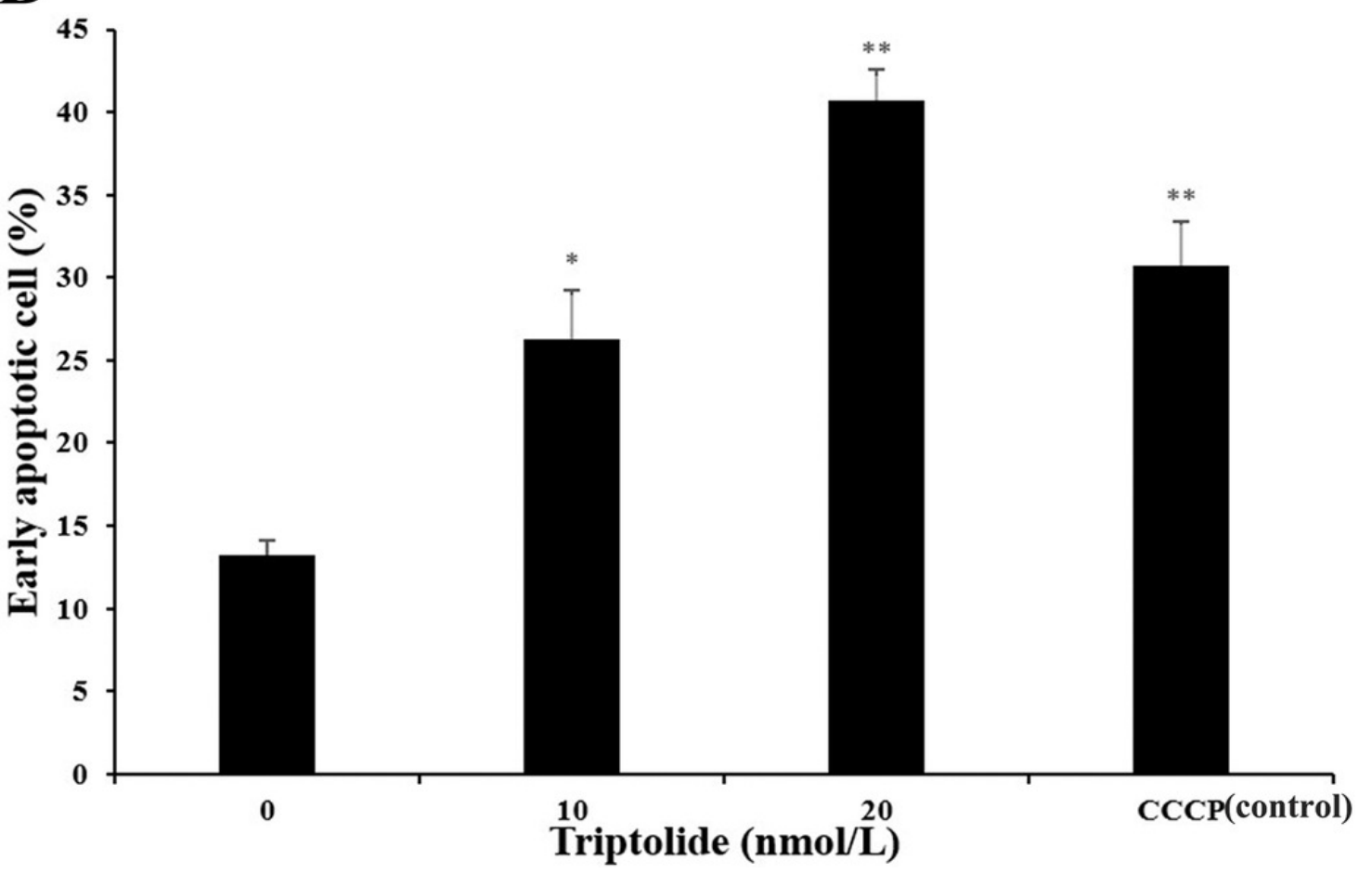




\section{Figure 3}

The 19 proteins screened by inverse docking. The docking pose of TPL binding to HSP90.

A) Inverse_docking scores calculated by GOLD of top 19 proteins. B) The docking pose of TPL binding to HSP90 (PDB ID: 5LNZ). The binding pocket of HSP90 protein displayed as a $\alpha$-helix with a surface. All compounds are shown with only backbone atoms.
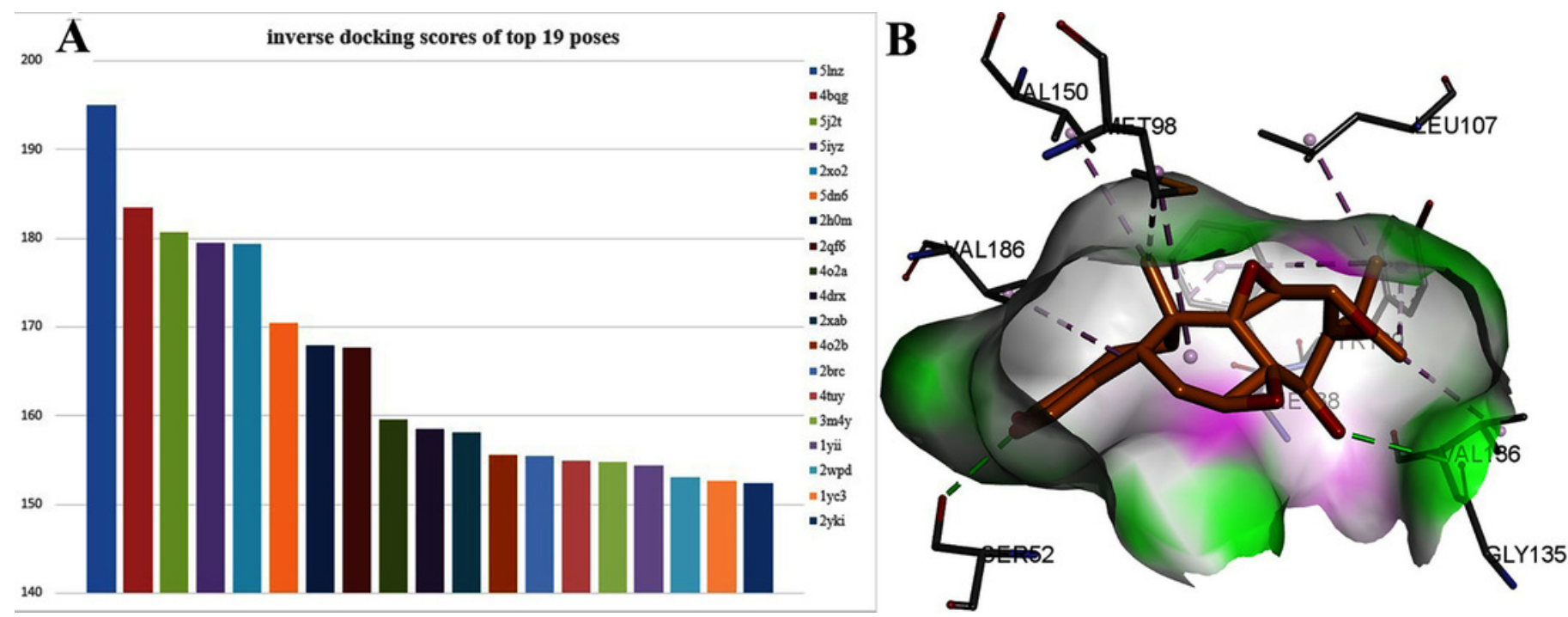
Figure 4

the results of differential gene expression in TPL-treated SKOV-3 cell .

Differentail expression profile of SKOV-3 proteome between 0 and $10 \mathrm{nmol} / \mathrm{L}$ TPL based on 2D-DIGE.

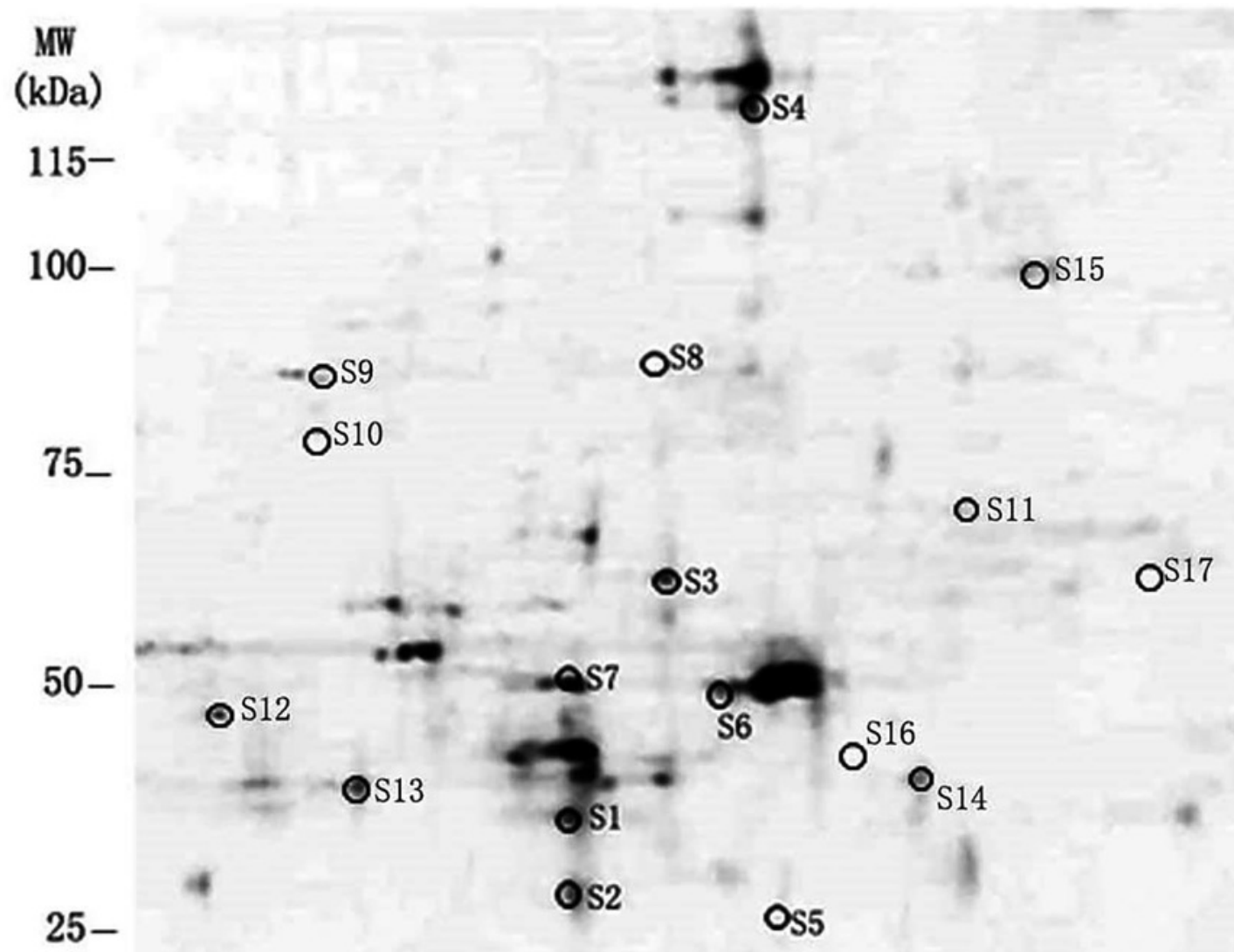

\section{$\mathrm{O}^{\mathrm{S} 18}$}

$12-$

pH 3

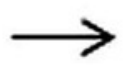

$\mathrm{pH} 10$ 


\section{Figure 5}

Validation of differential expression proteins by Western Blotting of TPL.

A) Validation of differential expression proteins by Western Blotting. B) The histogram of the relative protein expression levels (equates to protein/ $\beta$-actin). ${ }^{*} p \square 0.05$ vs. control $* * p \square 0.01$ vs. control

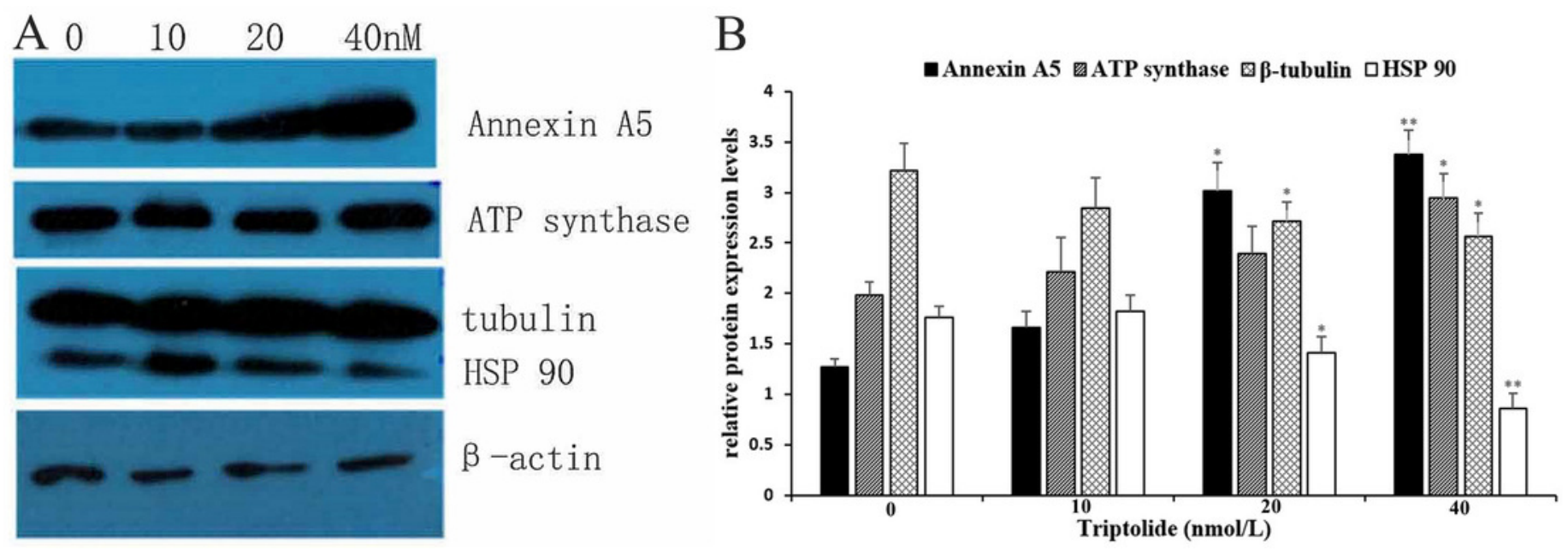




\section{Table $\mathbf{1}$ (on next page)}

The $\mathrm{IC}_{50}$ value of different drugs on SKOV-3 cells of TPL.

The IC50 value of cisplatinum and triptolide. Values are means of three experiments. IC $\mathrm{C}_{50}$, compound concentration required to inhibit tumor cell proliferation by $50 \%$. 
1

Table 1. The $\mathrm{IC}_{50}$ value of different drugs on SKOV-3 cells

\begin{tabular}{ccc}
\hline & \multicolumn{2}{c}{$\mathrm{IC}_{50} \mathrm{a}, \mathrm{b}$} \\
\cline { 2 - 3 } time (h) & triptolide $(\mathrm{nmol} / \mathrm{L})$ & $\begin{array}{c}\text { cisplatinum } \\
(\mu \mathrm{mol} / \mathrm{L})\end{array}$ \\
\hline 24 & $70.3 \pm 1.17$ & $33.0 \pm 1.77$ \\
48 & $40.0 \pm 0.89$ & $19.2 \pm 1.32$ \\
72 & $31.7 \pm 1.23$ & $9.6 \pm 0.74$ \\
\hline
\end{tabular}

2 a Values are means of three experiments.

$3 \mathrm{~b}^{\mathrm{b}} \mathrm{IC}_{50}$, compound concentration required to inhibit tumor cell proliferation by $50 \%$.

4

5

6

7 


\section{Table 2 (on next page)}

Up-regulated and down-regulated genes after treatment with TPL in SKOV-3 cells.

Differential gene expression in TPL-treated SKOV-3 cell. There are the known or proposed function of the identified proteins. 
1 Table 2. Up-regulated and down-regulated genes after treatment with TPL in SKOV-3 cells.

\begin{tabular}{|c|c|c|c|c|c|}
\hline $\begin{array}{l}\text { Spot } \\
\text { No. }\end{array}$ & $\begin{array}{l}\text { Identified } \\
\text { protien }\end{array}$ & Aession No. & $\mathbf{M r} / \mathbf{p I}$ & $\begin{array}{l}\text { Ratio } \\
\text { (TPL/Control) }\end{array}$ & Known or proposed function \\
\hline \multicolumn{6}{|c|}{ Up-regulated proteins } \\
\hline S1 & Annexin A5 & gi|4502107 & $35936.8 / 4.93$ & 3.28 & anticoagulation and apoptosis \\
\hline S2 & $\begin{array}{l}\text { Tropomyosin } \\
\text { alpha-3 chain }\end{array}$ & gi|669633291 & $28720 / 4.69$ & 2.27 & regulate the stability of actin \\
\hline S3 & $\begin{array}{l}\text { ATP synthase } \\
\text { subunit beta }\end{array}$ & gi|32189394 & $56559.9 / 5.26$ & 2.55 & a key enzyme in bioenergetics of a living cell \\
\hline S4 & $\begin{array}{l}\text { POTE ankyrin } \\
\text { domain family } \\
\text { member E }\end{array}$ & gi|134133226 & $121363.4 / 5.83$ & 2.04 & $\begin{array}{l}\text { regulate signaling between the inside and outside of } \\
\text { cells }\end{array}$ \\
\hline S5 & $\begin{array}{l}\text { Rho GDP- } \\
\text { dissociation } \\
\text { inhibitor }\end{array}$ & gi|961818162 & $22974 / 5.56$ & 2.13 & $\begin{array}{l}\text { inhibit cell carcinogenesis, infiltration and } \\
\text { metastasis }\end{array}$ \\
\hline S6 & $\begin{array}{l}\text { Actin, } \\
\text { cytoplasmic }\end{array}$ & gi|45382927 & $41736 / 5.29$ & 2.06 & maintain cell morphology \\
\hline \multicolumn{6}{|c|}{ Down-regulated proteins } \\
\hline S7 & $\begin{array}{l}\text { Tubulin beta- } \\
4 \mathrm{~B} \text { chain }\end{array}$ & gi| 5174735 & $49831 / 4.79$ & -2.39 & cell division \\
\hline S8 & $\begin{array}{l}\text { Heat shock } \\
\text { protein HSP } \\
\text { 90-alpha }\end{array}$ & gi|154146191 & $84659.7 / 4.94$ & -3.05 & maintain protein conformation \\
\hline
\end{tabular}

2

3

4

5 


\section{Table 3 (on next page)}

Expression amount of relative mRNA in SKOV-3 cells treated with TPL at qRT-PCR assay.

The results reveals that TPL markedly up-regulates the levels of Annexin A5 and ATP

synthase proteins as well as down-regulates the levels of $\beta$-Tubulin and HSP90 in ovarian cancer cell lines. 
1 Table 3. Expression amount of relative mRNA in SKOV-3 cells treated with TPL at qRT-PCR assay. $(n=3$, 2 mean \pm s)

\begin{tabular}{ccccc}
\multirow{2}{*}{$\begin{array}{c}\text { Triptolide } \\
(\mathrm{nmol} / \mathrm{L})\end{array}$} & \multicolumn{4}{c}{ Relative expression amount of mRNA } \\
\cline { 2 - 5 } & Annexin A5 & ATP synthase & $\beta$-Tubulin & HSP 90 \\
\hline 0 & 1 & 1 & 1 & 1 \\
10 & $1.55 \pm 0.06^{* *}$ & $1.37 \pm 0.15^{*}$ & $0.76 \pm 0.13$ & $0.67 \pm 0.08$ \\
20 & $3.68 \pm 0.04^{* *}$ & $2.79 \pm 0.11^{* *}$ & $0.38 \pm 0.19^{*}$ & $0.42 \pm 0.06^{* *}$ \\
40 & $6.34 \pm 0.07^{* *}$ & $4.08 \pm 0.08^{* *}$ & $0.11 \pm 0.12^{* *}$ & $0.21 \pm 0.09^{* *}$ \\
\hline
\end{tabular}

$3 * p<0.05$ vs. control $* * p<0.01$ vs. control

4 